\title{
PSIKOEDUKASI BIMBINGAN KARIR SISWA PADA GURU SMA DATUK BATU HAMPAR PEKANBARU
}

\author{
Puti Febrina Niko*, Ajeng Safitri, Baidarus, Abunawas \\ Prodi Ilmu Komunikasi, Fakultas Ilmu Komunikasi \\ Universitas Muhammadiyah Riau \\ email: putifebrina@umri.ac.id
}

\begin{abstract}
The large number of career types and education available makes most high school students experience balance, unpreparedness and stress in career decision making. Career neglect and choosing a career on the basis of following a friend leads to negative impacts on the students: selection of further studies of origin, unsuitable selection of talent and failure in a career for not seeing self potential. SMA Datuk Batu Hampar is one of the private schools in Pekanbaru that has no Counseling Guidance teacher who helps and guides students to face the problems. Therefore, the psychoeducation of students career guidance to teachers is expected to increase the knowledge and skills of teachers in helping students determine future careers. The methods used in this psychoeducation are lecture method and Questionnaire based on the student case. Evaluation is done at the beginning and end of psychoeducation implementation by providing a questionnaire of knowledge about student career guidance. Based on SPSS analysis using different test of Paired Samples Test, it is known that there is difference of teacher knowledge level about career guidance from before and after given psychoeducation with $t$ value $=-6,280$ and significant value 0,000 ( $p$ $<0,05)$. It is also known that there is an increase of mean before and after psychoeducation of student career guidance from 3,12 to 5,53.
\end{abstract}

Keywords: Psychoeducation; career guidance; career; students; high school teacher

\begin{abstract}
Abstrak
Banyaknya jenis karier dan pendidikan yang tersedia menyebabkan sebagian besar siswa SMA mengalami kembimbangan, ketidaksiapan dan stres dalam pembuatan keputusan karier. Kekurangpedulian terhadap karier dan memilih karier atas dasar mengikuti teman mengakibatkan dampak negatif bagi siswa yaitu pemilihan studi lanjut secara asal, pemilihan kerja tidak sesuai bakat dan kegagalan dalam berkarier karena tidak melihat potensi diri. SMA Datuk Batu Hampar merupakan salah satu sekolah swasta di Pekanbaru yang tidak memiliki guru Bimbingan Konseling (BK) yang berperan membantu dan membimbing siswa menghadapi permasalahannya. Oleh karena itu, psikoedukasi bimbingan karier siswa kepada guru diharapkan mampu meningkatkan pengetahuan dan keterampilan guru dalam membantu siswa/i menentukan karier di masa depan. Metode yang digunakan dalam psikoedukasi ini adalah metode ceramah dan Tanya jawab berdasarkan kasus siswa. Evaluasi dilakukan saat awal dan akhir pelaksanaan psikoedukasi dengan memberikan angket pengetahuan mengenai bimbingan karier siswa. Berdasarkan analisa SPSS menggunakan uji beda Paired Samples Test diketahui ada perbedaan tingkat pengetahuan guru mengenai bimbingan karier dari sebelum dan sesudah diberikan psikoedukasi dengan nilai $t=$ $-6,280$ dan nilai signifikan 0,000 ( $p<0,05)$. Diketahui pula adanya peningkatan rerata sebelum dan sesudah dilakukan psikoedukasi bimbingan karier siswa dari 3,12 menjadi 5,53.
\end{abstract}

Kata Kunci: Psikoedukasi, Bimbingan karier, Karier, Siswa,Guru SMA 


\section{PENDAHULUAN}

Peserta didik Sekolah Menengah Kejuruan Atas (SMA) berpikir rasional agar memiliki kejelasan arah dan tujuan karier. Perencanaan karier ini dimaksudkan untuk mempersiapkan individu tersebut dalam mengoptimalkan potensi yang dimilikinya. Setiap individu berhak untuk menentukan arah perencanaan kariernya ke depan. Creed dkk (2006) berpendapat bahwa sebanyak $50 \%$ siswa mengalami kebingungan berkaitan dengan pengambilan keputusan karier. Hal ini tidaklah mengejutkan karena ada begitu banyak jenis karier dan pendidikan tersedia, untuk itu terlebih dahulu perlu mengetahui kebutuhan seseorang, nilai-nilai yang diyakini dan tujuan karier yang akan menjadi pilihannya

Hasil penelitian Amin Budiman (2012) melaporkan bahwa; 90\% siswa SMA di Kabupaten Bandung menyatakan bingung dalam memilih karir untuk masa depan. Pada kenyataan, siswa SMA juga belum bisa mencapai tugas perkembangan karier. Siswa SMA masih ragu dan tidak memiliki kesiapan membuat keputusan karier yang tepat bagi masa depan. Fakta ini menyatakan bahwa banyak remaja mengalami kebimbangan, ketidaksiapan dan stres dalam pembuatan keputusan karier. Kurang peduli terhadap karier, serta pilihan atas dasar mengikuti teman jika terus dibiarkan akan mengakibatkan dampak negatif. Akibat dampak negatif tersebut adalah, pemilihan studi lanjut secara asal, dan pemilihan kerja tidak sesuai bakat, serta tanpa melihat kemampuan dalam diri individu akan menjerumuskan pada kegagalan karier. Oleh karena itu sangat dibutuhkan peran guru dalam memberikan education touch (menciptakan suasana yang mendukung untuk kesuksesan pendidikan), yang peduli, yang dapat memberikan dukungan, memotivasi, mengingatkan, memberi kesempatan, memberi tantangan, dan sebagainya (Depdiknas, 2006).

Guru di sekolah menengah semakin diharapkan mengambil peran aktif dalam terselenggaranya program bimbingan, selaras dengan fungsi di struktur kehidupan sekolah. Undang-Undang Republik Indonesia Nomor Tahun 2003 tentang Sistem Pendidikan Nasional menyatakan bahwa Bimbingan dan Konseling (BK) sebagai bagian integral dari sistem pendidikan. Para guru BK atau konselor menawarkan layanan BK untuk membantu peserta didik dalam mengoptimalkan perkembangan individual mereka, termasuk dukungan untuk membuat pilihian yang terkait dengan pekerjaan.

Sekolah Menengah Atas (SMA) Datuk Batu Hampar merupakan salah satu sekolah menengah swasta yang ada di pekanbaru yang beralamat Jl. Hangtuah Gg.Soponyono No.1 Sail Tenayan Raya. Berdasarkan hasil survey berupa wawancara dan observasi, sekolah ini belum memiliki guru bimbingan konseling sehingga peranannya digantikan oleh guru wali kelas ketika ditemukan permasalahan yang dialami oleh para siswa. Guru wali kelas di sekolah memiliki latar belakang keilmuan sesuai dengan mata pelajar yang diajarkan. Hal inilah yang mendasari pengabdian masyarakat dengan mengambil tema psikoedukasi bimbingan karier siswa pada guru SMA. Pemberian psikoedukasi ini diharapkan membawa dampak positif untuk sekolah menengah Atas (SMA) dalam meningkatkan pengetahuan dan keterampilan guru 
dalam mendampingin siswa/siswi di sekolah.

Tujuan dari pengabdian masyarakat ini adalah mengembangkan pengetahuan dan keterampilan penyelesaian masalah guru terhadap siswa/siswi di sekolah terutama dalam membantu membimbing karier di masa depan. Dengan dilaksanakannya pengabdian masyarakat ini maka diharapkan guru SMA, khususnya guru wali kelas, mendapat pengetahuan dan keterampilan dalam menyelesaikan permasalahan siswa-siswi di Sekolah Menengah Atas (SMA).

\section{METODE PENELITIAN}

Kegiatan pengabdian ini diawali dengan survey Tim ke lokasi pengabdian masyarakat dan berkoordinasi dengan pihak sekolah. Survey yang dilakukan Tim pengabdian berupa wawancara dan observasi untuk mendapatkan gambaran umum di SMA Datuk Batu Hampar.

Kegiatan pengabdian pada masyarakat dilaksanakan dengan metode ceramah dan tanya jawab yang dilaksanakan selama 3 jam. Adapun tahapan-tahapan dalam pelaksanaan kegiatannya adalah sebagai berikut: 1) Asesmen awal berupa angket pengetahuan untuk mengetahui pengetahuan guru SMA tentang bimbingan karier siswa di sekolah, sebelum dilakukan kegiatan Psikoedukasi Bimbingan Karier Siswa pada Guru SMA Datuk Batu Hampar Pekanbaru; 2) Penyampaian materi Bimbingan Karier Siswa pada Guru SMA Datuk Batu Hampar Pekanbaru; 3) Tanya jawab mengenai kasus atau permasalahan siswa yang dihadapi guru di sekolah; 4) Evaluasi akhir dilakukan dengan memberikan angket pengetahuan setelah kegiatan Psikoedukasi Bimbingan Karier Siswa pada Guru SMA.
Psikoedukasi bimbingan karier ditujukan untuk meningkatkan pengetahuan dan keterampilan guru SMA dalam membimbing siswa/i meraih masa depan dengan tepat dan terarah.. Evaluasi hasil pelatihan dilakukan selama proses dan setelah kegiatan pelatihan dilaksanakan.

Psikoedukasi adalah suatu bentuk pendidikan ataupun pelatihan terhadap seseorang dengan gangguan psikiatri yang bertujuan untuk proses treatment dan rehabilitasi. Sasaran dari psikoedukasi adalah untuk mengembangkan dan meningkatkan penerimaan pasien terhadap penyakit ataupun gangguan yang ia alami, meningkatkan pertisipasi pasien dalam terapi, dan pengembangan coping mechanism ketika pasien menghadapi masalah yang berkaitan dengan penyakit tersebut. (Goldman, 1998 dikutip dari Bordbar \& Faridhosseini, 2010).

Menurut Shertzer dan Stone (dalam Yusuf \& Nurihsan, 2009), bimbingan sebagai proses bantuan kepada individu agar mampu memahami diri dan lingkungan. Sedangkan menurut Sunaryo Kartadinata, bimbingan sebagai proses membantu individu untuk mencapai perkembangan optimal. Tujuan bimbingan pada akhirnya adalah supaya siswa mampu mengatur kehidupan sendiri, mempunyai pandangan sendiri dan mampu bertanggung jawab atas tindakan-tindakan yang diperbuatnya (Nurihsan, 2005). Kita dapat melihat bahwa sekarang tidak sedikit siswa-siswi memiliki persoalan dan masalah yang terkadang tidak bisa diselesaikan dan tanggungjawab. Siswa-siswa perlu diberi bimbingan dan konseling agar mampu menolong diri sendiri dan mengambil keputusan sendiri untuk masa depan. 
ASCA (Amerika School Counselor Association) mengemukakan bahwa konseling adalah hubungan tatap muka yang bersifat rahasia, penuh dengan sikap penerimaan dan pemberian kesempatan dari konselor kepada klien, konselor mempergunakan pengetahuan dan keterampilan untuk membantu kliennnya mengatasi masala-masalahnya.

Jadi, Bimbingan dan konseling yaitu suatu bantuan yang diberikan oleh konselor kepada konseli agar konseling mampu menyelesaikan masalah yang dihadapinya dan juga mampu mengembangkan potensi yang dimilikinya

Perencanaan karier menurut Borg, dkk (2006) ialah suatu kegiatan untuk mempertimbangkan melakukan hal-hal yang hendak dicapai dan membuat langkah-langkah pencapaiannya.

Model pengembangan karier yang baik adalah sistem pengembangan karier yang mengutamakan pentingnya pemahaman individu akan pemahaman diri, pemahaman pekerjaan serta orientasi terhadap dunia kerja, sehingga akan menghasilkan suatu keputusan pilihan karier yang relatif menetap, yang biasa disebut dengan kristalisasi pilihan karier.

Menurut Jaffe dan Scott (Kummerow, 1991), perencanaan karier adalah proses bertahap yang terdiri dari lima aspek. Berikut adalah penjelasannya: a) Menilai diri sendiri; b) Mengeksplorasi peluang; c)Menyusun rencana karier; d) Melakukan tindakan (implementasi); e) Mengevaluasi hasil.

Evaluasi psikoedukasi bimbingan karier siswa pada guru SMA dilakukan dengan melihat perbedaan sebelum dan sesudah diberikan psikoedukasi, dengan menggunakan analisis SPSS Paired Samples Test. Dimana diharapkan pengetahuan guru tentang bimbingan karier siswa setelah diberikan psikoedukasi lebih tinggi daripada sebelum dilakukan psikoedukasi.

\section{HASIL PEMBAHASAN}

Kegiatan pengabdian kepada masyarakat ini dilaksanakan di SMA Datuk Raja Hampar Jl. Hangtuah Gg. Soponyono No.1 Kel. Sail Kec. Tenayan Raya Pekanbaru, Kota Pekanbaru, Riau. Terlaksananya kegiatan ini sesuai dengan jadwal yang telah ditetapkan dan disepakati oleh sekolah.

Pengabdian kepada masyarakat ini dimulai dengan melakukan tahap persiapan dengan lakukan survey dan permohonan izin kepada pihak SMA Datuk Batu Hampar Pekanbaru sebagai tempat pelaksanaan pengabdian ini. Selain itu pada tahap persiapan juga mencari informasi jumlah peserta dan waktu pelaksanaan psikoedukasi bimbingan karier siswa pada guru SMA Datuk Batu Hampar Pekanbaru. Setelah waktu pelaksanaan disepakati, tim dari Dosen Psikologi Islam Fakultas Studi Islam menyusun jadwal pelaksanaan dan membuat kesepakatan dengan pihak sekolah SMA Datuk Batu Hampar Pekanbaru.

Kegiatan ini dilaksanakan dalam rangka catur dharma Perguruan Tinggi Muhammadiyah, yang salah satunya adalah pengabdian pada masyarakat. Kegiatan ini diberikan untuk menambah menambah pengetahuan tentang bimbingan karier siswa pada guru SMA Datuk Batu Hampar, dimana saat ini tidak ada guru Bimbingan Konseling di SMA tersebut.

Pada tahap pelaksanaan kegiatan ini dimulai dengan tahapan persiapan, tahapan persiapan dimana tim pelaksana kegiatan melakukan briefing untuk penyiapan perlengkapan psikoedukasi, 
membagi tugas masing-masing pembicara, menyiapkan para peserta psikoedukasi bimbingan karier pada siswa, menyiapkan materi psikoedukasi yang berhubungan dengan bimbingan karier siswa.

Tahapan pelaksanaan kegiatan dilaksanakan sesuai dengan waktu yang telah di sepakati pada tanggal 26 Februari 2018 bertempat di aula SMA Datuk Batu Hampar Pekanbaru. Tahapan pelaksanaan kegiatan dimulai dengan menjelaskan materi tentang bimbingan konseling, kemudian menjelaskan materi mengenai bimbingan karier siswa. Tahapan pelaksanan selanjutnya yaitu tanya jawab berdasarkan kasus yang ada di sekolah.

Tahapan psikoedukasi diberikan kepada semua guru SMA Datuk Batu Hampar Pekanbaru. Materi dan tanya jawab berlangsung pada saat kegiatan berlangsung, yaitu dari pukul 09.00 12.00 WIB. Evaluasi pada tahap pertama telah sesuai dengan indikator dan rancangan evaluasi diperoleh data sebagai berikut:

1. Jumlah peserta yang hadir sebanyak 17 orang dari 22 orang guru SMA Datuk Batu Hampar Pekanbaru sehingga tingkat kehadiran mencapai 77,3\%.

2. Semua peserta mengisi angket pengetahuan mengenai bimbingan karier siswa pada saat sebelum dan sesudah dilaksanakan psikoedukasi bimbingan karier siswa.

3. Peserta terlihat antusias selama mengikuti kegiatan hingga selesai.

4. Berdasarkan hasil pengolahan data sebelum dan sesudah psikoedukasi, terjadi peningkatan pengetahuan guru mengenai bimbingan karier siswa dengan dibuktikan ada peningkatan rerata sebelum dilakukan psikoedukasi bimbingan karier siswa sebesar 3,12 menjadi 5,53 setelah diberikan psikoedukasi. Selain itu, diketahui ada perbedaan tingkat pengetahuan guru mengenai bimbingan karier dari sebelum dan sesudah diberikan psikoedukasi melalui analisa paired samples test dengan nilai $\mathrm{t}=-6,280$ dan nilai signifikan 0,000 ( $\mathrm{p}<0,05$ ). Pengolahan data menggunakan SPSS 22 dengan menggunakan metode Paired Samples T Test. Uji t sampel berpasangan atau Paired Samples $T$ Test digunakan untuk menguji perbedaan rata-rata antara dua kelompok data yang berpasangan.

5. Setelah dilakukan psikoedukasi bimbingan karier siswa diharapkan guru-guru SMA Datuk Batu Hampar Pekanbaru memiliki pengetahuan yang lebih baik dibandingkan sebelum diberikan psikoedukasi. Selain itu, para guru diharapkan bisa melakukan bimbingan karier kepada siswa sesuai dengan tahapan yang telah diberikan saat psikoedukasi.

Evaluasi kegiatan secara umum berhasil dengan baik dan memuaskan peserta maupun pembicara. Peserta berharap di tahun-tahun berikutnya mendapatkan pelatihan bimbingan karier siswa agar memiliki keterampilan yang memadai dalam menghadapi permasalahan siswa di sekolah.

\section{KESIMPULAN}

Secara keseluruhan kegiatan pengabdian masyarakat melalui psikoedukasi bimbingan karier siswa berjalan baik dan lancar. Psikoedukasi ini 
memberikan pengetahuan tentang bimbingan karier siswa kepada guru SMA Datuk Batu Hampar Pekanbaru sebagai bekal guru dalam mengarahkan karier siswa berdasarkan potensi yang dimilikinya. Berdasarkan analisa data sebelum dan sesudah diberikan psikoedukasi, diketahui bahwa ada perbedaan pengetahuan guru yang sangat signifikan mengenai bimbingan karier siswa pada guru SMA Datuk Batu Hampar Pekanbaru, dimana nilai rerata sesudah diberikan psikoedukasi lebih tinggi dibandingkan sebelum diberikan psikoedukasi bimbingan karier siswa.

\section{UCAPAN TERIMAKASIH}

Terimakasih kami ucapkan kepada semua pihak yang mendukung kelancaran pengabdian ini terutama untuk SMA Datuk Batu Hampar Pekanbaru yang telah memberikan waktu dan kerja sama dalam proses pengabdian masyarakat. Selain itu, kepada LP2M dan Tim pengabdian Dosen yang telah memberi kesempatan dan kerjasama dalam terlaksana proses pengabdian.

\section{DAFTAR PUSTAKA}

1. Amin, Budiman. (2002). Manajemen Bimbingan pada SMU di Kabupaten Bandung. Jurnal Psikolog Pendidikan dan Bimbingan vol.2 November 2002. 259-266

2. Bardick, A.D., Bernes, K.B., Magnusson, K.C., \& Witko, K.D. (2006). Junior High School Students Career Plans for The Future. Journal of Career Development, 32, 250-271.

3. Bordbar, Mohammad. Faridhosseini, Farhad. 2010. Psychoeducation for Bipolar Mood Disorder. Jurnal:
Clinical, Research, Treatment Approaches to Affective Disorders.

4. Brog, T., Bright, J., \& Pryor, R. (2006). The Butterfly Model of Careers: Illustrating How Planning and Chance Can Be Integrated In The Careers of Seccondary School Students. Australian Journal of Career Development, 15, 2-11.

5. Creed, P., Patton, W., \& Prideaux, L.A. (2006). Causal Relationship Between Career Indecision and Career Decision-Making Self Efficacy. Journal of Career Development, 33 (1), 47-65

6. Depdiknas .2006. Permendiknas No 22 Tahun 2006 Tentang Standar Isi. Jakarta : Depdiknas

7. Kummerow, J.M. (1991). New Direction in Career Planning. California: CPP Book.

8. Nurihsan, Achmad Junika. 2005. Strategi Layanan Bimbingan dan Konseling. Bandung:PT. Refika Aditama, Cet. Ke-1

9. Sugiharto, DYP dan Mulawarman. 2007. Psikologi Konseling. Semarang: UNNES

10. Yusuf, S., \& Nurihsan, J. (2009). Landasan Bimbingan dan Konseling. Bandung: PT Remaja Rosdakarya 